\title{
Discovery of $\mathrm{HC}_{3} \mathrm{O}^{+}$in space: The chemistry of O-bearing species in $\mathrm{TMC}-1^{\star}$
}

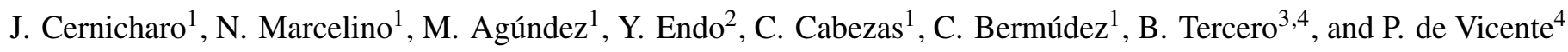 \\ ${ }^{1}$ Grupo de Astrofísica Molecular, Instituto de Física Fundamental (IFF-CSIC), C/ Serrano 121, 28006 Madrid, Spain \\ e-mail: jose.cernicharo@csic.es \\ 2 Department of Applied Chemistry, Science Building II, National Chiao Tung University, 1001 Ta-Hsueh Rd., Hsinchu 30010, \\ Taiwan \\ 3 Observatorio Astronómico Nacional (IGN), C/ Alfonso XII, 3, 28014 Madrid, Spain \\ ${ }^{4}$ Centro de Desarrollos Tecnológicos, Observatorio de Yebes (IGN), 19141 Yebes, Guadalajara, Spain
}

Received 6 September 2020 / Accepted 30 September 2020

\begin{abstract}
Using the Yebes $40 \mathrm{~m}$ and IRAM $30 \mathrm{~m}$ radio telescopes, we detected a series of harmonically related lines with a rotational constant $B_{0}=4460.590 \pm 0.001 \mathrm{MHz}$ and a distortion constant $D_{0}=0.511 \pm 0.005 \mathrm{kHz}$ towards the cold dense core TMC-1. High-level-oftheory ab initio calculations indicate that the best possible candidate is protonated tricarbon monoxide, $\mathrm{HC}_{3} \mathrm{O}^{+}$. We have succeeded in producing this species in the laboratory and observed its $J_{u}-J_{l}=2-1$ and 3-2 rotational transitions. Hence, we report the discovery of $\mathrm{HC}_{3} \mathrm{O}^{+}$in space based on our observations, theoretical calculations, and laboratory experiments. We derive an abundance ratio $N\left(\mathrm{C}_{3} \mathrm{O}\right) / N\left(\mathrm{HC}_{3} \mathrm{O}^{+}\right) \sim 7$. The high abundance of the protonated form of $\mathrm{C}_{3} \mathrm{O}$ is due to the high proton affinity of the neutral species. The chemistry of O-bearing species is modelled, and predictions are compared to the derived abundances from our data for the most prominent O-bearing species in TMC-1.
\end{abstract}

Key words. astrochemistry - ISM: molecules - ISM: individual objects: TMC-1 - line: identification - molecular data

\section{Introduction}

The cold dark core TMC-1 presents an interesting carbon-rich chemistry that leads to the formation of long neutral carbonchain radicals and their anions (see Cernicharo 2020a and references therein). Cyanopolyynes, which are stable molecules, are also particularly abundant in TMC-1 (see Cernicharo 2020b and references therein). The chemistry of this peculiar object produces a large abundance of nearly saturated species, such as $\mathrm{CH}_{3} \mathrm{CHCH}_{2}$; this species may mostly be a typical molecule of hot cores (Marcelino et al. 2007). The first polar benzenic ring, $\mathrm{C}_{6} \mathrm{H}_{5} \mathrm{CN}$ (McGuire et al. 2018), was also detected in this object, while benzene itself has only been detected to date towards post-asymptotic giant branch objects (Cernicharo et al. 2001). Hence, it has been a surprising result to see that, with an almost dominant carbon chemistry, O-bearing carbon chains such as $\mathrm{CCO}$ (Ohishi et al. 1991), $\mathrm{C}_{3} \mathrm{O}$ (Matthews et al. 1984), $\mathrm{HC}_{5} \mathrm{O}$, and $\mathrm{HC}_{7} \mathrm{O}$ are also produced in TMC-1 (Cordiner et al. 2017; McGuire et al. 2017). The formation path for $\mathrm{HC}_{5} \mathrm{O}$ and $\mathrm{HC}_{7} \mathrm{O}$ is still a mystery, as is the reason for the non-detection of $\mathrm{HC}_{3} \mathrm{O}$, $\mathrm{HC}_{4} \mathrm{O}$, and $\mathrm{HC}_{6} \mathrm{O}$ in the same cloud. The O-bearing carbon chain $\mathrm{HC}_{2} \mathrm{O}$ has, however, been observed in cold dense clouds (Agúndez et al. 2015a).

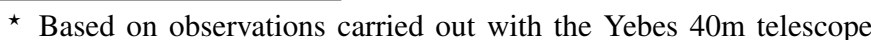
(projects 19A003 and 20A014) and the Institut de Radioastronomie Millimétrique (IRAM) 30m telescope. The $40 \mathrm{~m}$ radio telescope at Yebes Observatory is operated by the Spanish Geographic Institute (IGN, Ministerio de Transportes, Movilidad y Agenda Urbana); IRAM is supported by INSU/CNRS (France), MPG (Germany), and IGN (Spain).
}

All long carbon chains containing oxygen that have been observed so far in interstellar clouds are neutral. Cationic species related to these oxygen-bearing neutral species are thought to play an important role in the synthesis of different neutral molecules in cold dense clouds. Moreover, it has been suggested that some of them may be sufficiently long-lived to be abundant (Petrie et al. 1993), although to date no such cation has been observed. In general, the abundance of polyatomic cations in cold interstellar clouds is relatively low because they react quickly with electrons. In addition to the widespread $\mathrm{HCO}^{+}$and $\mathrm{N}_{2} \mathrm{H}^{+}$, the other polyatomic cations detected in cold interstellar clouds are $\mathrm{HCS}^{+}$(Thaddeus et al. 1981), $\mathrm{HCNH}^{+}$ (Schilke et al. 1991), $\mathrm{HC}_{3} \mathrm{NH}^{+}$(Kawaguchi et al. 1994), $\mathrm{HCO}_{2}^{+}$ (Turner et al. 1999; Sakai et al. 2008), $\mathrm{NH}_{3} \mathrm{D}^{+}$(Cernicharo et al. 2013), $\mathrm{NCCNH}^{+}$(Agúndez et al. 2015b), $\mathrm{H}_{2} \mathrm{COH}^{+}$(Bacmann et al. 2016), $\mathrm{H}_{2} \mathrm{NCO}^{+}$(Marcelino et al. 2018), and $\mathrm{HC}_{5} \mathrm{NH}^{+}$ (Marcelino 2020). These species are the protonated forms of abundant neutral species. The abundance ratio between a protonated molecule and its neutral counterpart, $\left[\mathrm{MH}^{+}\right] /[\mathrm{M}]$, is sensitive to the degree of ionization and thus to various physical parameters of the cloud, as well as the formation and destruction rates of the cation (Agúndez et al. 2015b). The protonated form is mainly formed by proton transfer to the neutral and destroyed by dissociative recombination with electrons. It is interesting to note that both chemical models and observations suggest a trend in which the abundance ratio $\left[\mathrm{MH}^{+}\right] /[\mathrm{M}]$ increases with the increasing proton affinity of $\mathrm{M}$ (Agúndez et al. 2015b).

In this Letter, we report the detection of four harmonically related lines that belong to a molecule with a ${ }^{1} \Sigma$ ground electronic state towards the cold dark core TMC-1. From microwave 
laboratory experiments supported by ab initio calculations, we conclude that the carrier is $\mathrm{HC}_{3} \mathrm{O}^{+}$, the protonated form of $\mathrm{C}_{3} \mathrm{O}$. We present a detailed observational study of the most relevant O-bearing species in this cloud and discuss these results in the context of state-of-the-art chemical models.

\section{Observations}

New receivers, built as part of the Nanocosmos project ${ }^{1}$ and installed at the Yebes $40 \mathrm{~m}$ radio telescope, were used for the observations of TMC- 1 . The $Q$-band receiver consists of two HEMT (high electron mobility transistor) cold amplifiers covering the $31.0-50.3 \mathrm{GHz}$ band with horizontal and vertical polarizations. Receiver temperatures vary from $22 \mathrm{~K}$ at $32 \mathrm{GHz}$ to $42 \mathrm{~K}$ at $50 \mathrm{GHz}$. The spectrometers are $2 \times 8 \times 2.5 \mathrm{GHz}$ FFTs (Fast Fourier Transform) with a spectral resolution of $38.1 \mathrm{kHz}$, which provides full coverage of the $Q$-band in both polarizations. The main beam efficiency varies from 0.6 at $32 \mathrm{GHz}$ to 0.43 at $50 \mathrm{GHz}$.

The observations leading to the line survey in $Q$-band towards TMC-1 $\left(\alpha_{J 2000}=4^{\mathrm{h}} 41^{\mathrm{m}} 41.9^{\mathrm{s}}\right.$ and $\delta_{J 2000}=+25^{\circ} 41^{\prime}$ $\left.27.0^{\prime \prime}\right)$ were performed over several sessions carried out between November 2019 and February 2020. The observing procedure was frequency switching with a frequency throw of $10 \mathrm{MHz}$. The nominal spectral resolution of $38.1 \mathrm{kHz}$ was used for the final spectra. The sensitivity varies along the $Q$-band between 1 and $3 \mathrm{mK}$, which is a considerable improvement over previous line surveys in the 31-50 GHz frequency range (Kaifu et al. 2004).

The IRAM $30 \mathrm{~m}$ data come from a line survey performed towards TMC-1 and B1. These observations have been described by Marcelino et al. (2007) and Cernicharo et al. (2013).

The antenna temperature intensity scale for the two telescopes used in this work was calibrated using two absorbers at different temperatures and the atmospheric transmission model ATM (Cernicharo 1985; Pardo et al. 2001). Calibration uncertainties were adopted to be $10 \%$. All the data have been analysed using the GILDAS package ${ }^{2}$.

\section{Results}

Most of the weak lines found in our survey of TMC-1 can be assigned to known species and their isotopologues, and only a few remain unidentified (Marcelino et al., in prep.). As previously mentioned, the level of sensitivity has been increased by a factor of 5-10 with respect to previous line surveys performed with other telescopes at these frequencies (Kaifu et al. 2004). Frequencies for the unknown lines were derived by assuming a local standard of rest velocity of $5.83 \mathrm{~km} \mathrm{~s}^{-1}$, a value that was derived from the observed transitions of $\mathrm{HC}_{5} \mathrm{~N}$ and its isotopologues in our line survey (Cernicharo 2020a). Our new data towards TMC-1 have allowed us to detect the anions $\mathrm{C}_{3} \mathrm{~N}^{-}$ and $\mathrm{C}_{5} \mathrm{~N}^{-}$(Cernicharo 2020a), the cation $\mathrm{HC}_{5} \mathrm{NH}^{+}$(Marcelino 2020), and the isomer $\mathrm{HC}_{4} \mathrm{NC}$ of $\mathrm{HC}_{5} \mathrm{~N}$ (Cernicharo 2020b), in addition to dozens of already known molecules.

The assignment of the observed features was done using the CDMS catalogue (Müller et al. 2005) and the MADEX code (Cernicharo 2012). Within the still unidentified features in our survey, we found two lines with a harmonic relation of 5:4 between them. The precision of this ratio is better than $2 \times 10^{-5}$. Taking into account the density of lines in TMC-1, the possibility that the harmonic relation between these two lines is the result of a fortuitous agreement is very small. Moreover, we explored our

$\begin{array}{ll}1 & \text { https://nanocosmos.iff.csic.es/ } \\ 2 & \text { http://WWW.iram. fr/IRAMFR/GILDAS }\end{array}$

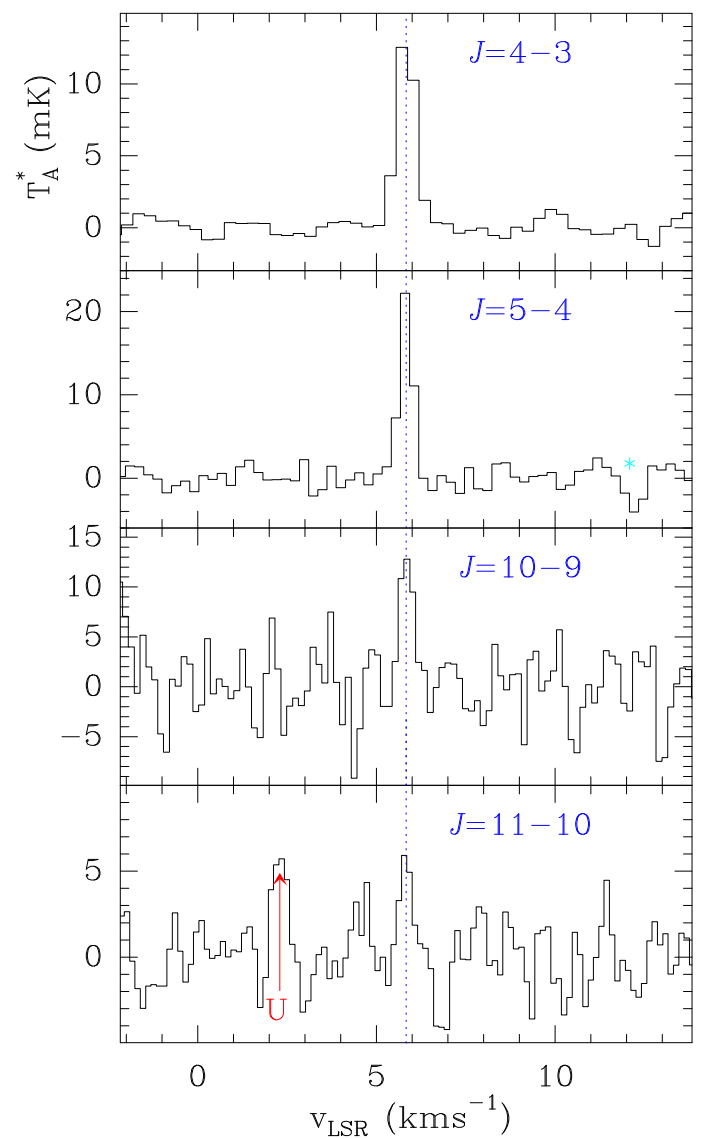

Fig. 1. Observed lines of the new molecule found in the $31-50 \mathrm{GHz}$ domain towards TMC-1. The abscissa corresponds to the local standard of rest velocity in $\mathrm{km} \mathrm{s}^{-1}$. Frequencies and intensities for the observed lines are given in Table 1. The ordinate is the antenna temperature corrected for atmospheric and telescope losses in $\mathrm{mK}$. The $J=19-18$ line is only detected at a $3.5 \sigma$ level. Spectral resolution is $38.1 \mathrm{kHz}$.

data at $3 \mathrm{~mm}$ (Marcelino et al. 2007) and found two additional lines, the $J=10-9$ line at $89209.749 \mathrm{MHz}$ and the $J=11-10$ transition at $98130.267 \mathrm{MHz}$. The frequency relation 4:5:10:11 between the four lines strongly suggests that the carrier is a linear molecule with a ${ }^{1} \Sigma$ ground electronic state. The observed lines are shown in Fig. 1, and the derived line parameters are given in Table 1.

For a linear molecule in a ${ }^{1} \Sigma$ electronic state, the frequencies of its rotational transitions follow the standard expression $v(J \rightarrow$ $J-1)=2 B_{0} J-4 D_{0} J^{3}$. By fitting the frequencies of the lines given in Table 1 , we derive $B_{0}=4460.58989 \pm 0.00096 \mathrm{MHz}$ and $D_{0}=51.06 \pm 0.47 \mathrm{~Hz}$. The standard deviation of the fit is $10.3 \mathrm{kHz}$.

\subsection{Potential carriers of the series of lines}

An important piece of information to know when searching for the carrier of the lines is that the $J=4-3$ line does not show any evidence of hyperfine splitting. A molecule with a terminal CN group will produce observable hyperfine splitting for its $J=4-3$ transition. Hence, if the molecule contains a $\mathrm{CN}$ group, it should be an isocyano species (-NC terminal group). The typical hyperfine quadrupole splitting of a terminal $\mathrm{NH}$ group will also be unresolved for the $J=4-3$ transition.

In TMC-1, only polyatomic molecules containing $\mathrm{H}, \mathrm{C}, \mathrm{N}$, $\mathrm{O}$, and $\mathrm{S}$ have been found so far. In order to evaluate the possible structure of the carrier, we can consider other species that 
Table 1. Observed line parameters for the new molecule in TMC-1.

\begin{tabular}{lccccc}
\hline \hline$J_{u}-J_{l}$ & $\begin{array}{c}v_{\mathrm{obs}}{ }^{(a)} \\
(\mathrm{MHz})\end{array}$ & $\begin{array}{c}v_{o}-v_{c}{ }^{(b)} \\
(\mathrm{kHz})\end{array}$ & $\begin{array}{c}\int T_{A}^{*} \mathrm{~d} v^{(c)} \\
\left(\mathrm{mK} \mathrm{km} \mathrm{s}^{-1}\right)\end{array}$ & $\begin{array}{c}\Delta v^{(d)} \\
\left(\mathrm{km} \mathrm{s}^{-1}\right)\end{array}$ & $\begin{array}{c}T_{A}^{*} \\
(\mathrm{mK})\end{array}$ \\
\hline $4-3$ & 35684.590 & -0.6 & $9.1 \pm 0.5$ & $0.63 \pm 0.03$ & 13.8 \\
$5-4$ & 44605.748 & +4.4 & $10.7 \pm 0.6$ & $0.45 \pm 0.03$ & 22.5 \\
$10-9$ & 89209.744 & -11.3 & $6.4 \pm 1.0$ & $0.44 \pm 0.09$ & 13.8 \\
$11-10$ & 98130.286 & 8.0 & $2.4 \pm 0.7$ & $0.40 \pm 0.10$ & 5.8 \\
\hline
\end{tabular}

Notes. ${ }^{(a)}$ Observed frequencies adopting a $v_{\text {LSR }}$ of $5.83 \mathrm{~km} \mathrm{~s}^{-1}$ for TMC1. The uncertainty is $10 \mathrm{kHz}$ for all the lines. ${ }^{(b)}$ Observed minus calculated frequencies in $\mathrm{kHz} .{ }^{(c)}$ Integrated line intensity in $\mathrm{mK} \mathrm{km} \mathrm{s}^{-1}$. ${ }^{(d)}$ Line width at half intensity derived by fitting a Gaussian line profile to the observed transitions (in $\mathrm{km} \mathrm{s}^{-1}$ ).

have a similar rotational constant. Molecules such as $\mathrm{HC}_{3} \mathrm{~N}$ $\left(B_{0} \sim 4549 \mathrm{MHz}\right), \mathrm{HC}_{3}^{15} \mathrm{~N}\left(B_{0} \sim 4417 \mathrm{MHz}\right), \mathrm{C}_{4} \mathrm{H}$ and $\mathrm{C}_{4} \mathrm{D}$ $\left(B_{0} \sim 4758 \mathrm{MHz}\right.$ and $4416.4 \mathrm{MHz}$, respectively), the radical $\mathrm{HCCCO}$ (quasi-linear with $(\mathrm{B}+\mathrm{C}) / 2 \sim 4533 \mathrm{MHz}), \mathrm{NCCNH}^{+}$ $\left(B_{0} \sim 4438 \mathrm{MHz}\right)$, or $\mathrm{H}_{2} \mathrm{C}_{4}((B+C) / 2 \sim 4466 \mathrm{MHz})$ all provide a strong indication of the presence of four heavy atoms of $\mathrm{C}, \mathrm{N}$, and/or $\mathrm{O}$, as well as a hydrogen or deuterium atom. Species containing sulphur, such as HCCS, HCCCS, or HNCS, have rotational constants that are very different from the observed one.

In fact, despite being an asymmetrical molecule, the species that has a close match to our rotational constant is $\mathrm{H}_{2} \mathrm{C}_{4}$; its case has to be considered in detail as its series of $J_{0, J}$ transitions are in good harmonic relation. Its lines are particularly prominent in TMC-1, $\mathrm{T}_{A}^{*} \sim 0.2 \mathrm{~K}$. Although the measured $(B+C) / 2$ value is $\sim 6 \mathrm{MHz}$ above the observed one, its isotopologues $\mathrm{H}_{2} \mathrm{C}^{13} \mathrm{CCC}$ and $\mathrm{H}_{2} \mathrm{CC}^{13} \mathrm{CC}$ could have a slightly lower $(B+C) / 2$. Its four ${ }^{13} \mathrm{C}$ isotopologues have been observed in the laboratory (McCarthy \& Thaddeus 2002). Those corresponding to the second and third carbon in the molecule have $(B+C) / 2 \sim 4454.8$ and $4443.8 \mathrm{MHz}$, respectively. Hence, they do not match our $B$ rotational constant. Moreover, taking into account the derived ${ }^{12} \mathrm{C} /{ }^{13} \mathrm{C}$ abundance ratio in TMC-1 of $\sim 90$ (Cernicharo 2020b; Taniguchi et al. 2016), the expected intensities for the four ${ }^{13} \mathrm{C}$ isotopologues of $\mathrm{H}_{2} \mathrm{C}_{4}$ are ten times weaker than the intensity of the observed lines (see Table 1 and Fig. 1). Finally, the rotational constant of the HDCCCC isotopologue is smaller than that of our series of lines (Kim \& Yamamoto 2005).

The cationic species derived from the protonation of CCCO, $\mathrm{HCCCO}^{+}$, was calculated by Botschwina (1989) to have a ${ }^{1} \Sigma$ ground electronic state with $B_{0}=4454 \pm 10 \mathrm{MHz}$. Recently, Thorwirth et al. (2020) performed high-level ab initio calculations and derived a rotational constant $B_{0} \sim 4460.4 \mathrm{MHz}$, which matches our observed value very well. This species may be formed from the reaction of $\mathrm{C}_{3} \mathrm{O}$ with cations such as $\mathrm{H}_{3}^{+}$and $\mathrm{HCO}^{+}$. The proton affinity of $\mathrm{C}_{3} \mathrm{O}$ was calculated by Botschwina (1989) to be quite high, $885 \pm 5 \mathrm{~kJ} \mathrm{~mol}^{-1}$. From the observed trend of increasing protonated-to-neutral abundance ratios with increasing proton affinity (Agúndez et al. 2015b), a high abundance ratio $\mathrm{HC}_{3} \mathrm{O}^{+} / \mathrm{C}_{3} \mathrm{O}$ is expected.

Although $\mathrm{HC}_{3} \mathrm{O}^{+}$seems to be the best candidate, we have to explore other possible species derived from the isomers of $\mathrm{NCCNH}^{+}$, which also has a very close rotational constant of 4438.012 MHz (Gottlieb et al. 2000). In particular, $\mathrm{CNCNH}^{+}$, the protonated form of $\mathrm{CNCN}$, which has also been found in space (Agúndez et al. 2018), could also be a good candidate. Other isomers with the proton on the terminal carbon atom are possible candidates as well (see Table 2). The protonated forms of the isomers of $\mathrm{HC}_{3} \mathrm{~N}-\mathrm{HCCNCH}^{+}$and $\mathrm{HNCCCH}^{+}-$could also have rotational constants around the observed value. The neutral isomers of cyanoacetylene have been observed towards
Table 2. Rotational constants and electric dipole moments of potential candidates.

\begin{tabular}{|c|c|c|c|}
\hline Molecule & $\begin{array}{c}B_{0} \\
(\mathrm{MHz})\end{array}$ & $\begin{array}{c}D \\
(\mathrm{kHz})\end{array}$ & $\begin{array}{l}\mu^{(a)} \\
\text { (D) }\end{array}$ \\
\hline New species ${ }^{(b)}$ & 4460.6 & 0.510 & \\
\hline $\mathrm{HC}_{3} \mathrm{O}^{+(c)}$ & 4460.5 & 0.469 & 3.41 \\
\hline $\mathrm{HCNCN}^{+}(d)$ & 4792.8 & 0.554 & 8.33 \\
\hline $\mathrm{HNCNC}^{+(d)}$ & 4899.1 & 0.511 & 3.96 \\
\hline $\mathrm{HCNNC}^{+(d)}$ & 5210.8 & 0.611 & 6.17 \\
\hline $\mathrm{HCCNCH}^{+}(d)$ & 4646.4 & 0.458 & 3.45 \\
\hline $\mathrm{HNCCCH}^{+}(d)$ & 4327.0 & 0.395 & 1.15 \\
\hline $\mathrm{HCCCO}^{-(d)}$ & 4246.8 & 0.311 & 0.31 \\
\hline
\end{tabular}

Notes. ${ }^{(a)}$ Dipole moment calculated at the $\operatorname{CCSD}(\mathrm{T})-\mathrm{F} 12 / \mathrm{cc}-\mathrm{pCVTZ}$ F12 level of theory. ${ }^{(b)}$ Values derived from the frequencies observed in TMC-1 (see Sect. 3). ${ }^{(c)} B_{0}$ and $D$ values scaled by the ratio Exp/Calc. of the corresponding parameter $\mathrm{HC}_{3} \mathrm{~N}$ species (see Table 3). ${ }^{(d)}$ All the parameters for these species have been calculated at the $\operatorname{CCSD}(\mathrm{T})$ F12/cc-pCVTZ-F12 level of theory. No corrections using scaling factors have been applied.

TMC-1 and are abundant (see Cernicharo 2020b and references therein), and the protonated form of $\mathrm{HC}_{3} \mathrm{~N}$ has also been detected in this source (see Marcelino 2020 and references therein).

\subsection{Quantum chemical calculations and assignment to $\mathrm{HC}_{3} \mathrm{O}^{+}$}

In order to obtain precise geometries and spectroscopic molecular parameters that help in the assignment of the observed lines, we carried out high-level ab initio calculations for all the species mentioned above. Table 2 shows the results from the geometry optimization calculations carried out at the CCSD(T)F12/cc-pCVTZ-F12 level of theory (Raghavachari et al. 1989; Adler et al. 2007; Knizia et al. 2009; Hill et al. 2010; Hill \& Peterson 2010). This method has been proven to be suitable for accurately reproducing the molecular geometry of analogue molecules (Cernicharo et al. 2019; Marcelino 2020). As can be seen, $\mathrm{HCNCN}^{+}, \mathrm{HNCNC}^{+}, \mathrm{HCNNC}^{+}$, and $\mathrm{HCCNCH}^{+}$all have rotational constants much larger than those derived from the frequencies observed in TMC-1. Hence, they can be excluded as carriers of the observed lines.

The $B_{e}$ value obtained for $\mathrm{HC}_{3} \mathrm{O}^{+}$is $4457.383 \mathrm{MHz}$ (see Table 3), which is very close to that derived for the new molecule. To obtain a more precise value for the rotational constant for $\mathrm{HC}_{3} \mathrm{O}^{+}$, we should estimate $B_{0}$ by the zero-point vibrational contribution to the rotational constant and then calibrate this value using an experimental over theoretical ratio as scaling factor for analogue molecular species. At this point, two options are possible: $\mathrm{C}_{3} \mathrm{O}$, which shares practically the same molecular structure, or $\mathrm{HC}_{3} \mathrm{~N}$, which is an isoelectronic species of $\mathrm{HC}_{3} \mathrm{O}^{+}$. Structural calculations at the CCSD(T)-F12/cc-pCVTZF12 level of theory give a $B_{e}$ value for $\mathrm{C}_{3} \mathrm{O}$ of $4795.4 \mathrm{MHz}$, not very close to the experimental one of 4810.885 (33) (Brown et al. 1983). This discrepancy may be attributed to the floppy nature of $\mathrm{C}_{3} \mathrm{O}$, for which large zero-point vibrational contributions are expected (Botschwina \& Reisenauer 1991). For this reason, $\mathrm{C}_{3} \mathrm{O}$ is not a good reference system to calibrate the $\mathrm{HC}_{3} \mathrm{O}^{+}$calculations, and, as such, we used $\mathrm{HC}_{3} \mathrm{~N}$ for this purpose. Table 3 shows the results for our calculations for $\mathrm{HC}_{3} \mathrm{~N}$ and those for $\mathrm{HC}_{3} \mathrm{O}^{+}$. After adding zero-point vibrational contribution to the $B_{e}$ rotational constant and scaling by the ratio 
Table 3. Theoretical values for the spectroscopic parameters of $\mathrm{HC}_{3} \mathrm{O}^{+}$(all in $\mathrm{MHz}$ ).

\begin{tabular}{|c|c|c|c|c|c|}
\hline \multirow[b]{2}{*}{ Parameter } & \multicolumn{2}{|c|}{$\mathrm{HC}_{3} \mathrm{~N}$} & \multicolumn{3}{|c|}{$\mathrm{HC}_{3} \mathrm{O}^{+}$} \\
\hline & Calc. ${ }^{(a)}$ & Exp. ${ }^{(b)}$ & Calc. ${ }^{(a)}$ & Scaled. ${ }^{(c)}$ & Scaled. ${ }^{(d)}$ \\
\hline$B_{e}$ & 4549.911 & & 4457.383 & & \\
\hline Vib-Rot. Corr. & 4.899 & & 1.630 & & \\
\hline$B_{0}$ & 4544.215 & $4549.058558(40)$ & 4455.753 & 4460.502 & 4460.443 \\
\hline$D \times 10^{-3}$ & 0.501 & $0.5442223(91)$ & 0.432 & 0.469 & 0.471 \\
\hline
\end{tabular}

Notes. ${ }^{(a)}$ This work; the $B_{0}$ rotational constant has been estimated using the $B_{e}$ value calculated at the CCSD(T)-F12/cc-pCVTZ-F12 level of theory and corrected with vibration-rotation interaction estimated at the MP2/cc-pVTZ level of theory. The centrifugal distortion constant has been calculated at the MP2/cc-pVTZ level of theory. ${ }^{(b)}$ Thorwirth et al. (2000). ${ }^{\left({ }^{(}\right)}$This work; scaled by the ratio Exp/Calc. of the corresponding parameter for the $\mathrm{HC}_{3} \mathrm{~N}$ species. ${ }^{(d)}$ Thorwirth et al. (2020).

Experimental/Calculated for $\mathrm{HC}_{3} \mathrm{~N}$, we obtained a $B_{0}$ for $\mathrm{HC}_{3} \mathrm{O}^{+}$of $4460.502 \mathrm{MHz}$, which agrees perfectly with that derived from the TMC-1 lines. The centrifugal distortion value, obtained in the same manner but at the MP2/cc-pVTZ level of theory, is $0.469 \mathrm{kHz}$, which is compatible with that obtained from the fit of the lines. The results of our calculations are in agreement with those obtained by Thorwirth et al. (2020), which are also shown in Table 3. Finally, another potential candidate is $\mathrm{HC}_{3} \mathrm{O}^{-}$. However, our calculations indicate a rotational constant $\sim 210 \mathrm{MHz}$ below the observed one and a very low permanent dipole moment (see Table 3). Hence, from the arguments provided in the previous section and our calculations, we conclude that the best candidate for the carrier of the observed lines is $\mathrm{HC}_{3} \mathrm{O}^{+}$.

\subsection{Laboratory detection of $\mathrm{HC}_{3} \mathrm{O}^{+}$}

In order to confirm our assignment of the astrophysical lines to $\mathrm{HC}_{3} \mathrm{O}^{+}$, we measured its microwave spectrum using a BalleFlygare-type Fourier transform microwave (FTMW) spectrometer combined with a pulsed discharge nozzle (Endo et al. 1994; Cabezas et al. 2016), which has been used in the past to characterize other highly reactive molecules. The reactive transient species, $\mathrm{HC}_{3} \mathrm{O}^{+}$, was produced in a supersonic expansion by a pulsed electric discharge of a gas mixture of $\mathrm{C}_{2} \mathrm{H}_{2}(0.15 \%), \mathrm{CO}$ $(0.8 \%)$, and $\mathrm{H}_{2}(1.0 \%)$ diluted in $\mathrm{Ne}$, and with the application of a voltage of $800 \mathrm{~V}$ through the throat of the nozzle source. We searched for the $J=2-1$ and 3-2 rotational transitions of $\mathrm{HC}_{3} \mathrm{O}^{+}$, predicting their frequencies from the rotational constants derived in TMC-1. These frequency regions were scanned and two lines were observed, within a few kilohertz of the predicted frequencies, at 17842.3387 and $26763.4749 \mathrm{MHz}$ with an uncertainty of $5 \mathrm{kHz}$ (see Fig. 2). The following experimental results confirm that these lines belong to a transient species: (i) they disappear in the absence of electric discharge and (ii) the lines disappear when one of the reactants $\left(\mathrm{C}_{2} \mathrm{H}_{2}\right.$ or $\left.\mathrm{CO}\right)$ is removed from the gas mixture. No more lines at lower or higher frequencies $\left(J_{u}-J_{l}=1-0\right.$ and 4-3) could be observed due to the spectrum weakness and the worse performance of the spectrometer at those frequencies.

We definitively conclude that the carrier of the observed lines is protonated tricarbon monoxide $\left(\mathrm{HC}_{3} \mathrm{O}^{+}\right)$. By merging the laboratory and astrophysical data, we derive

$B_{0}=4460.58896 \pm 0.00057 \mathrm{MHz}$,

$D_{0}=50.64 \pm 0.30 \mathrm{~Hz}$,

which are the recommended constants for predicting the rotational spectrum of $\mathrm{HC}_{3} \mathrm{O}^{+}$. The standard deviation of the merged fit is $9.1 \mathrm{kHz}$. Frequency predictions have uncertainties $\leq 10 \mathrm{kHz}$

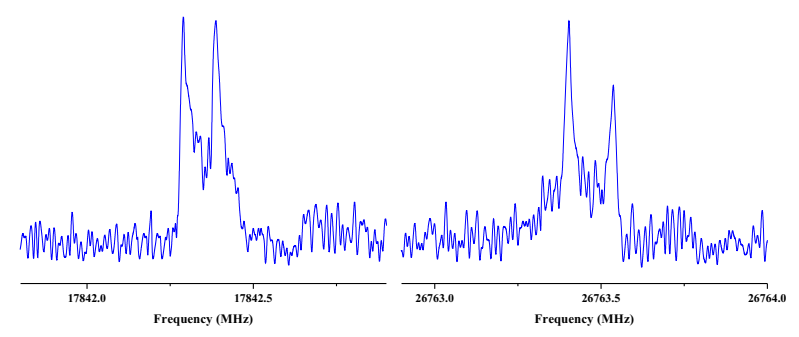

Fig. 2. FTMW spectra of $\mathrm{HC}_{3} \mathrm{O}^{+}$showing the 2-1 and 3-2 rotational transitions at 17842.3387 and $26763.4695 \mathrm{MHz}$, respectively. The spectra were achieved via 20000 shots of accumulation at a repetition rate of $10 \mathrm{~Hz}$. The coaxial arrangement of the adiabatic expansion and the resonator axis produces an instrumental Doppler doubling. The resonance frequencies are calculated as the average of the two Doppler components.

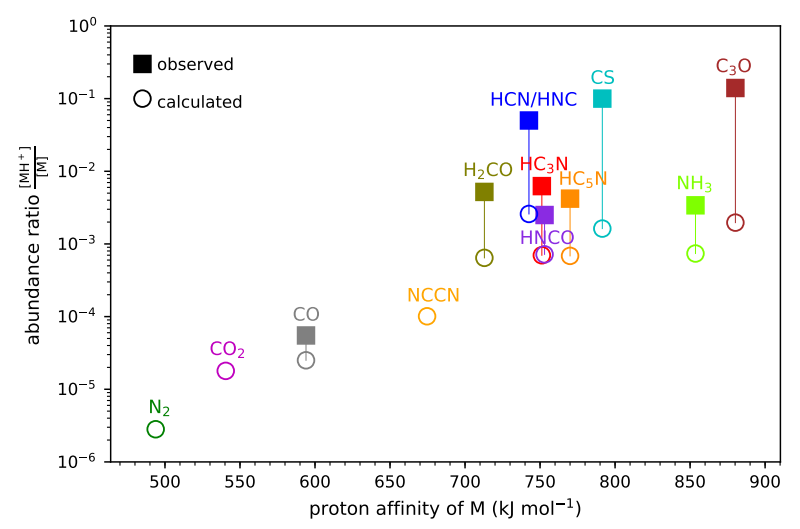

Fig. 3. Observed and calculated abundance ratios $\left[\mathrm{MH}^{+}\right] /[\mathrm{M}]$ in cold dense clouds as a function of the proton affinity of the neutral M. They are based on Agúndez et al. (2015b), with updates for $\mathrm{H}_{2} \mathrm{COH}^{+}$from Bacmann et al. (2016), for $\mathrm{H}_{2} \mathrm{NCO}^{+}$from Marcelino et al. (2018), for $\mathrm{HC}_{5} \mathrm{NH}^{+}$from Marcelino (2020), and for $\mathrm{HC}_{3} \mathrm{O}^{+}$from this study.

for transitions below $100 \mathrm{GHz}$ and $\leq 100 \mathrm{kHz}$ for those in the range $100-180 \mathrm{GHz}$ (see Table A.3).

\section{Discussion}

The detection of $\mathrm{HC}_{3} \mathrm{O}^{+}$in $\mathrm{TMC}-1$ provides a further clue regarding the chemistry of protonated molecules in cold dense clouds. Agúndez et al. (2015b) find a trend in which the abundance ratio $\mathrm{MH}^{+} / \mathrm{M}$ increases with the increasing proton affinity of the neutral $\mathrm{M}$. The $\mathrm{C}_{3} \mathrm{O}$ species has a very large proton affinity, $\sim 885 \pm 5 \mathrm{~kJ} \mathrm{~mol}^{-1}$ (Botschwina 1989). In 
fact, it is one of the largest proton affinities among abundant molecules in cold dark clouds. The observed abundance ratio $N\left(\mathrm{HC}_{3} \mathrm{O}^{+}\right) / N\left(\mathrm{C}_{3} \mathrm{O}\right)=0.14$ (see Appendix $\mathrm{A}$ and Table A.1) fits well with the expected value for a molecule with such a large proton affinity, according to the trend shown in Fig. 3. However, chemical model calculations similar to those presented in Agúndez et al. (2015b) predict an abundance ratio $\mathrm{HC}_{3} \mathrm{O}^{+} / \mathrm{C}_{3} \mathrm{O}$ of only $2 \times 10^{-3}$ at steady state, which is almost two orders of magnitude below the observed value. Part of the discrepancy may stem from the fact that rate constants for the main reactions of the formation (proton transfer from $\mathrm{H}_{3} \mathrm{O}^{+}, \mathrm{HCO}^{+}$, and $\mathrm{H}_{3}^{+}$) and destruction (dissociative recombination with electrons) of $\mathrm{HC}_{3} \mathrm{O}^{+}$are not known, and thus chemical networks like UMIST RATE12 (McElroy et al. 2013) and KIDA kida.uva.2014 (Wakelam et al. 2015a) adopt estimates for them. These estimates, however, should not be drastically different from the real ones. In general, protonated-to-neutral abundance ratios are underestimated by chemical models, probably because chemical networks miss important formation routes for the cation (see Agúndez et al. 2015b and Fig. 3). In the case of $\mathrm{HC}_{3} \mathrm{O}^{+}$, additional formation routes may be provided by reactions of the ions $\mathrm{C}_{3} \mathrm{H}_{2}^{+}$and linear $\mathrm{C}_{3} \mathrm{H}_{3}^{+}$with $\mathrm{O}$ atoms, which is currently not considered in the aforementioned reaction networks. The reaction between $\mathrm{C}_{4} \mathrm{H}_{2}^{+}$and $\mathrm{O}$ atoms (e.g. Tenenbaum et al. 2006) is only an efficient route to $\mathrm{HC}_{3} \mathrm{O}^{+}$at very early times $\left(<10^{5} \mathrm{yr}\right)$, while reactions of $\mathrm{C}_{3} \mathrm{H}^{+}$with $\mathrm{O}_{2}$, $\mathrm{H}_{2} \mathrm{O}$, and $\mathrm{CO}_{2}$ (Herbst et al. 1984) are not a major route to $\mathrm{HC}_{3} \mathrm{O}^{+}$according to the chemical model. The sulphur analogue $\mathrm{HC}_{3} \mathrm{~S}^{+}$is a good candidate for detection given that $\mathrm{C}_{3} \mathrm{~S}$ has a very high proton affinity $\left(933 \mathrm{~kJ} \mathrm{~mol}^{-1}\right)$ and is around five times more abundant than $\mathrm{C}_{3} \mathrm{O}$. We searched for it in our line survey using the ab initio calculations of Thorwirth et al. (2020) and derive an upper limit to its column density of $3 \times 10^{11} \mathrm{~cm}^{-2}$, which implies an abundance ratio $N\left(\mathrm{HC}_{3} \mathrm{~S}^{+}\right) / N\left(\mathrm{C}_{3} \mathrm{~S}\right)<0.04$. The lower $\mathrm{MH}^{+} / \mathrm{M}$ ratio of $\mathrm{C}_{3} \mathrm{~S}$ compared to $\mathrm{C}_{3} \mathrm{O}$ probably stems from the fact that routes to $\mathrm{HC}_{3} \mathrm{O}^{+}$involving $\mathrm{O}$ atoms can be efficient because of the high abundance of neutral $\mathrm{O}$ atoms, while the sulphur analogous routes would be less efficient because atomic sulphur is expected to be preferably in ionized rather than neutral form.

In Table A.1, we present a comprehensive list of abundances derived from our data for O-bearing molecules in TMC-1. The chemistry of some of these species has already been discussed in detail, for example, in Agúndez et al. (2015a) and Wakelam et al. (2015b) for HCCO, in Loison et al. (2016) for the isomers $c-\mathrm{H}_{2} \mathrm{C}_{3} \mathrm{O}$ and $\mathrm{HCCCHO}$, and in McGuire et al. (2017) and Cordiner et al. (2017) for $\mathrm{HC}_{5} \mathrm{O}$ and $\mathrm{HC}_{7} \mathrm{O}$. These last O-bearing carbon chains deserve some discussion. They represent a new class of interstellar molecules and their chemistry is not yet well understood. Cordiner \& Chamley (2012) proposed that $\mathrm{HC}_{n} \mathrm{O}$ molecules may directly form through reactions of hydrocarbon anions $\mathrm{C}_{n} \mathrm{H}^{-}$with $\mathrm{O}$ atoms in a process of associative electron detachment. This mechanism, however, overestimates the abundances of $\mathrm{HC}_{6} \mathrm{O}, \mathrm{C}_{6} \mathrm{O}$, and $\mathrm{C}_{7} \mathrm{O}$ by one to two orders of magnitude (Cordiner et al. 2017). McGuire et al. (2017) proposed that $\mathrm{HC}_{n} \mathrm{O}$ molecules could form through radiative association reactions of $\mathrm{C}_{n} \mathrm{H}_{2}^{+}$and $\mathrm{C}_{n} \mathrm{H}_{3}^{+}$ions with $\mathrm{CO}$ followed by dissociative recombination with electrons. This mechanism explains the non-detection of $\mathrm{HC}_{6} \mathrm{O}$ in terms of a low reactivity between $\mathrm{C}_{5} \mathrm{H}_{2}^{+}$and $\mathrm{CO}$ (Adams et al. 1989), although it overestimates the abundance of $\mathrm{HC}_{4} \mathrm{O}$ by almost two orders of magnitude. The large abundance found for $\mathrm{HC}_{3} \mathrm{O}^{+}$suggests that reactions between hydrocarbon ions and atomic oxygen probably participate in the growth of these long O-bearing carbon chains.
Acknowledgements. The Spanish authors thank Ministerio de Ciencia e Innovación for funding support through projects AYA2016-75066-C2-1-P, PID2019-107115GB-C21. We also thank ERC for funding through Grant ERC-2013-Syg-610256-NANOCOSMOS. M. A. and C. B. thanks MICIN for grants RyC-2014-16277 and FJCI-2016-27983, respectively. Y. Endo thanks Ministry of Science and Technology of Taiwan through Grant MOST108-2113M-009-25.

\section{References}

Adler, T. B., Knizia, G., \& Werner, H.-J. 2007, J. Chem. Phys., 127, 221106 Adams, N. G., Smith, D., Giles, K., \& Herbst, E. 1989, A\&A, 220, 269 Agúndez, M., Cernicharo, J., \& Guélin, M. 2015a, A\&A, 577, L5 Agúndez, M., Cernicharo, J., de Vicente, P., et al. 2015b, A\&A, 579, L10 Agúndez, M., Marcelino, N., \& Cernicharo, J. 2018, ApJ, 861, L22 Bacmann, A., García-García, E., \& Faure, A. 2016, A\&A, 588, L8 Botschwina, P. 1989, J. Chem. Phys., 90, 4301

Botschwina, P., \& Reisenauer, H. P. 1991, Chem. Phys. Lett., 183, 217 Brown, R. D., Eastwood, F. W., Elmes, P. S., \& Godfrey, P. D. 1983, J. Am. Chem. Soc., 105, 6496

Cabezas, C., Guillemin, J.-C., \& Endo, Y. 2016, J. Chem. Phys., 145, 184304 Cernicharo, J. 1985, Internal IRAM report (Granada: IRAM)

Cernicharo, J. 2012, EAS Pub. Ser., 2012, 251, https://nanocosmos.iff. csic.es/?page_id=1619

Cernicharo, J., \& Guélin, M. 1987, A\&A, 176, 299

Cernicharo, J., Heras, A. M., Tielens, A. G. G. M., et al. 2001, ApJ, 546, L123

Cernicharo, J., Tercero, B., Fuente, A., et al. 2013, ApJ, 771, L10

Cernicharo, J., Cabezas, C., Pardo, J. R., et al. 2019, A\&A, 630, L2

Cernicharo, J., Marcelino, N., Pardo, J. R., et al. 2020a, A\&A, 641, L9

Cernicharo, J., Marcelino, N., Agundez, M., et al. 2020b, A\&A, 642, L8

Cordiner, M. A., \& Chamley, S. B. 2012, ApJ, 749, 120

Cordiner, M. A., Chamley, S. B., Kisiel, Z., et al. 2017, ApJ, 850, 187

Endo, Y., Kohguchi, H., \& Ohshima, Y. 1994, Faraday Discuss., 97, 341

Fossé, D., Cernicharo, J., Gerin, M., \& Cox, P. 2001, ApJ, 552, 168

Gottlieb, C. A., Aponi, A. J., McCarthy, M. C., \& Thaddeus, P. 2000, J. Chem. Phys., 113, 1910

Herbst, E., Smith, D., \& Adams, N. G. 1984, A\&A, 138, L13

Hill, J. G., \& Peterson, K. A. 2010, Phys. Chem. Chem. Phys., 12, 10460

Hill, J. G., Mazumder, S., \& Peterson, K. A. 2010, J. Chem. Phys., 132, 054108

Kaifu, N., Ohishi, M., Kawaguchi, K., et al. 2004, PASJ, 56, 69

Kawaguchi, K., Kasai, Y., Ishikawa, S., et al. 1994, ApJ, 420, L95

Kim, E., \& Yamamoto, S. 2005, J. Mol. Spectrosc., 233, 93

Knizia, G., Adler, T. B., \& Werner, H.-J. 2009, J. Chem. Phys., 130, 054104

Loison, J.-C., Agúndez, M., Marcelino, N., et al. 2016, MNRAS, 456, 4101

Matthews, H. E., Irvine, E., Friberg, F. M., et al. 1984, Nature, 310, 125

Marcelino, N., Cernicharo, J., Agúndez, M., et al. 2007, ApJ, 665, L127

Marcelino, N., Agúndez, M., Cernicharo, J., et al. 2018, A\&A, 612, L10

Marcelino, N., Agundez, M., Tercero, B., et al. 2020, A\&A, in press, https: //doi.org/10.1051/0004-6361/202039251

McCarthy, M. C., \& Thaddeus, P. 2002, J. Mol. Spectrosc., 211, 235

McElroy, D., Walsh, C., Markwick, A. J., et al. 2013, A\&A, 550, A36

McGuire, B. A., Burkhardt, M., Shingledecker, C. N., et al. 2017, ApJ, 843, L28

McGuire, B. A., Burkhardt, M., Kalenskii, S., et al. 2018, Science, 359, 202

Müller, H. S. P., Schlöder, F., Stutzki, J., \& Winnewisser, G. 2005, J. Mol. Struct., 742,215

Ohishi, M., Suzuki, H., Ishikawa, S.-I., et al. 1991, ApJ, 380, L39

Pardo, J. R., Cernicharo, J., \& Serabyn, E. 2001, IEEE Trans. Antennas Propag., 49, 12

Petrie, S., Bettens, R. P. A., Freeman, C. G., \& McEwan, M. J. 1993, MNRAS, 264, 862

Raghavachari, K., Trucks, G. W., Pople, J. A., \& Head-Gordon, M. 1989, Chem. Phys. Lett., 157, 479

Sakai, N., Sakai, T., Aikawa, Y., \& Yamamoto, S. 2008, ApJ, 675, L89

Schilke, P., Walmsley, C. M., Millar, T. J., \& Henkel, C. 1991, A\&A, 247, 487

Taniguchi, K., Ozeki, H., Saito, M., et al. 2016, ApJ, 817, 147

Tenenbaum, E. D., Apponi, A. J., Ziurys, L. M., et al. 2006, ApJ, 649, L17

Thaddeus, P., Guélin, M., \& Linke, R. A. 1981, ApJ, 246, L41

Thorwirth, S., Müller, H. S. P., \& Winnewisser, G. 2000, J. Mol. Spectrosc., 204, 133

Thorwirth, S., Harding, M. E., Asvany, O., et al. 2020, Mol. Phys., in press, https://doi.org/10.1080/00268976.2020.1776409

Turner, B. E., Terzieva, R., \& Herbst, E. 1999, ApJ, 518, 699

Wakelam, V., Loison, J.-C., Herbst, E., et al. 2015a, ApJS, 217, 20

Wakelam, V., Loison, J.-C., Hickson, K. M., \& Ruaud, M. 2015b, MNRAS, 453, L48 


\section{Appendix A: Observational data for O-bearing species in TMC1}

Table A.1. Column densities for relevant O-bearing species in TMC-1.

\begin{tabular}{|c|c|c|c|c|}
\hline Molecule & $N^{(a)}$ & $X^{(b)}$ & $N\left(\mathrm{CH}_{3} \mathrm{OH}\right) / N$ & \\
\hline $\mathrm{HCCCO}^{+}$ & $2.1(2) \times 10^{11}$ & $2.1 \times 10^{-11}$ & 229 & \\
\hline $\mathrm{HOCO}^{+}$ & $4.0(2) \times 10^{11}$ & $4.0 \times 10^{-11}$ & 120 & \\
\hline $\mathrm{H}_{2} \mathrm{COH}^{+}$ & $\leq 3.0 \times 10^{11}$ & $\leq 3.0 \times 10^{-11}$ & $\geq 160$ & \\
\hline $\mathrm{H}_{2} \mathrm{NCO}^{+}$ & $\leq 4.0 \times 10^{10}$ & $\leq 4.0 \times 10^{-12}$ & $\geq 1200$ & \\
\hline HNCO & $1.3(1) \times 10^{13}$ & $1.3 \times 10^{-9}$ & 3.7 & \\
\hline HCNO & $7.0(3) \times 10^{10}$ & $7.0 \times 10^{-12}$ & 686 & \\
\hline $\mathrm{HOCN}$ & $1.1(2) \times 10^{11}$ & $1.1 \times 10^{-11}$ & 437 & \\
\hline $\mathrm{CH}_{3} \mathrm{OH}$ & $4.8(3) \times 10^{13}$ & $4.8 \times 10^{-9}$ & 1 & $A+E$ \\
\hline $\mathrm{CCO}$ & $1.5(3) \times 10^{12}$ & $1.5 \times 10^{-10}$ & 32 & \\
\hline $\mathrm{CCCO}$ & $1.5(2) \times 10^{12}$ & $1.5 \times 10^{-10}$ & 32 & \\
\hline $\mathrm{CCCCO}$ & $\leq 1.2 \times 10^{11}$ & $\leq 1.2 \times 10^{-11}$ & $\geq 400$ & \\
\hline $\mathrm{CCCCCO}$ & $\leq 4.0 \times 10^{10}$ & $\leq 4.0 \times 10^{-12}$ & $\geq 1200$ & \\
\hline $\mathrm{HCOOH}$ & $1.4(2) \times 10^{12}$ & $1.4 \times 10^{-10}$ & 34 & \\
\hline $\mathrm{HCCO}$ & $1.0(2) \times 10^{12}$ & $1.0 \times 10^{-10}$ & 48 & \\
\hline $\mathrm{HCCCO}$ & $\leq 2.0 \times 10^{11}$ & $\leq 2.0 \times 10^{-11}$ & $\geq 240$ & \\
\hline $\mathrm{HCCCCO}$ & $\leq 3.0 \times 10^{11}$ & $\leq 3.0 \times 10^{-11}$ & $\geq 160$ & \\
\hline $\mathrm{HCCCCCO}$ & $1.8(2) \times 10^{12}$ & $1.8 \times 10^{-10}$ & 27 & \\
\hline HCCССCCO & $\leq 7.0 \times 10^{11}$ & $\leq 7.0 \times 10^{-11}$ & $\geq 59$ & \\
\hline НСССССССО & $\leq 9.0 \times 10^{11}$ & $\leq 9.0 \times 10^{-11}$ & $\geq 53$ & \\
\hline $\mathrm{H}_{2} \mathrm{CCO}$ & $1.4(2) \times 10^{13}$ & $1.4 \times 10^{-9}$ & 3.4 & $o+p$ \\
\hline $\mathrm{H}_{2} \mathrm{CCCO}$ & $\leq 1.1 \times 10^{11}$ & $\leq 1.1 \times 10^{-11}$ & $\geq 436$ & \\
\hline $\mathrm{c}-\mathrm{H}_{2} \mathrm{C}_{3} \mathrm{O}$ & $4.0(2) \times 10^{11}$ & $4.0 \times 10^{-11}$ & 120 & $o+p$ \\
\hline $\mathrm{HCCCHO}$ & $2.0(2) \times 10^{12}$ & $2.0 \times 10^{-10}$ & 240 & \\
\hline $\mathrm{H}_{2} \mathrm{CCCCO}$ & $\leq 1.2 \times 10^{11}$ & $\leq 1.2 \times 10^{-11}$ & $\geq 400$ & $o$ \\
\hline $\mathrm{CH}_{3} \mathrm{CHO}$ & $3.5(2) \times 10^{12}$ & $3.5 \times 10^{-10}$ & 14 & $A+E$ \\
\hline $\mathrm{NH}_{2} \mathrm{CHO}$ & $<5.0 \times 10^{10}$ & $<5.0 \times 10^{-12}$ & $>960$ & \\
\hline $\mathrm{HCCCCOH}$ & $\leq 1.0 \times 10^{11}$ & $\leq 1.0 \times 10^{-11}$ & $>480$ & \\
\hline
\end{tabular}

Notes. ${ }^{(a)}$ Column density in $\mathrm{cm}^{-2}$. Upper limits correspond to $3 \sigma$ values. ${ }^{(b)}$ Relative abundance to $\mathrm{H}_{2}$ assuming a total column density of molecular hydrogen of $10^{22} \mathrm{~cm}^{-2}$ (Cernicharo \& Guélin 1987).

In order to study the chemistry of O-bearing species in TMC-1, we explored the lines arising from these species in our line survey. The derived line parameters are given in Table A.2, and some selected lines are shown in Fig. A.1. Line parameters were derived by fitting a Gaussian line profile to the observed features. Rest frequencies were adopted from the MADEX code (Cernicharo 2012). In order to derive column densities, we assumed that all molecular species are thermalized at a temperature of $10 \mathrm{~K}$. Main beam efficiency (see Sect. 2) and source dilution in the beam were applied to all the observations. For the source dilution, we assumed a source radius of 40" (Fossé et al. 2001), that is to say, the source practically fills the main beam of the telescope at all observed frequencies. The derived column densities of detected O-bearing species in our survey were obtained using the MADEX code and are given in Table A.1. The $1 \sigma$ sensitivity of the survey is $\sim 0.6-0.7 \mathrm{mK}$ and $0.7-2.0 \mathrm{mK}$ below and above $40 \mathrm{GHz}$, respectively. Hence, the data allow us to derive very sensitive $3 \sigma$ upper limits for the column density of many O-bearing species, which are given in Table A.1. It is worth noting that although many lines of $\mathrm{HC}_{5} \mathrm{O}$ are detected in our survey, only upper limits have been obtained for $\mathrm{HC}_{7} \mathrm{O}$ lines, which has been reported previously by McGuire et al. (2017) and Cordiner et al. (2017) using line stacking.

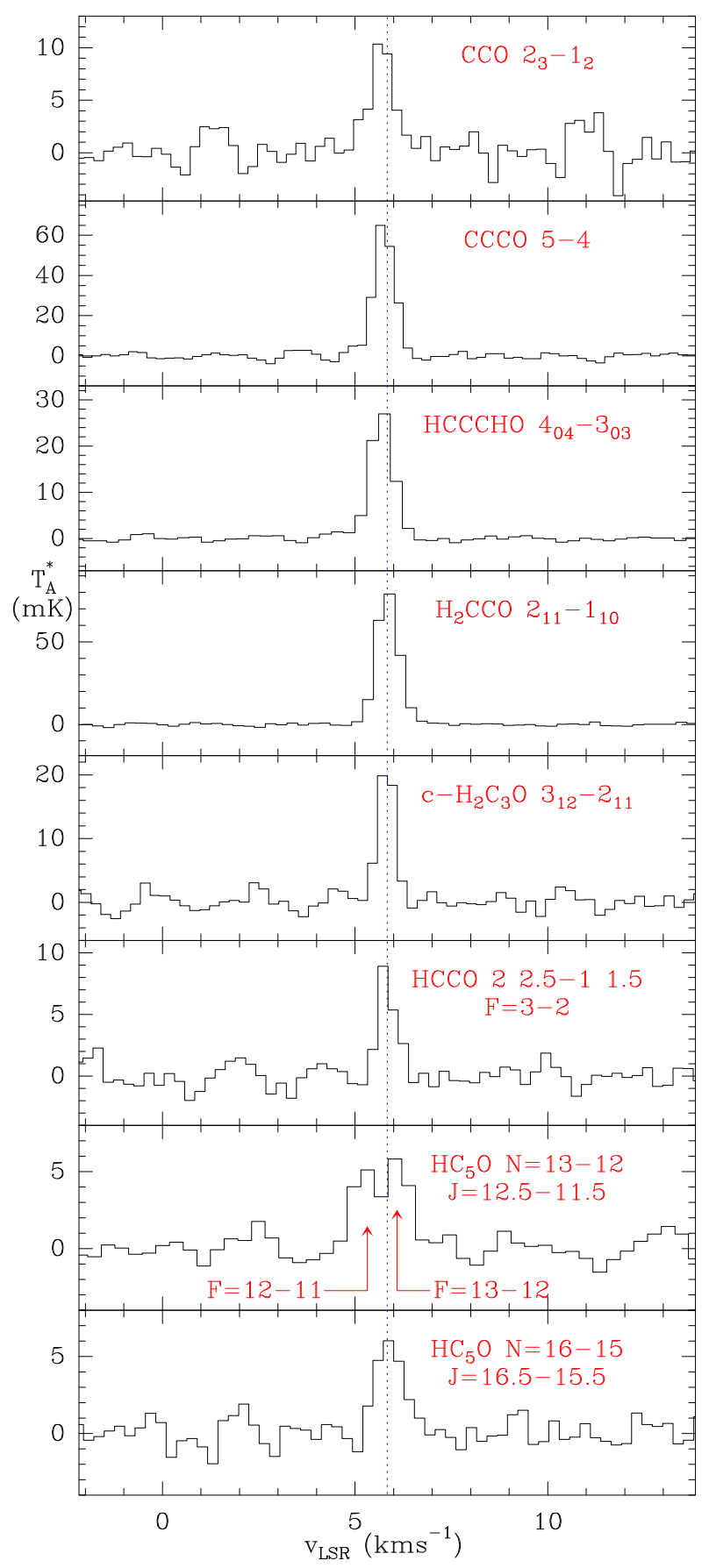

Fig. A.1. Selected lines of O-bearing species observed towards TMC1 in the $31-50 \mathrm{GHz}$ domain. The abscissa corresponds to the local standard of rest velocity in $\mathrm{km} \mathrm{s}^{-1}$. Frequencies and intensities for the observed lines are given in Table A.2. The ordinate is the antenna temperature corrected for atmospheric and telescope losses in $\mathrm{mK}$. Spectral resolution is $38.1 \mathrm{kHz}$.

Table A.3 provides the frequencies, uncertainties, upper energy levels, Einstein coefficients, and degeneracies for transitions up to $J=30-29$. This information is provided with the intent of facilitating the search for $\mathrm{HC}_{3} \mathrm{O}^{+}$in other sources and with other instruments. 
Table A.2. Derived line parameters for O-bearing species in TMC-1.

\begin{tabular}{|c|c|c|c|c|c|c|}
\hline Molecule & Transition & $\begin{array}{l}\nu_{\text {rest }}(a) \\
(\mathrm{MHz})\end{array}$ & $\underset{\left(\mathrm{mK} \mathrm{km} \mathrm{s}^{-1}\right)}{\int_{A}^{*} \mathrm{~d} v^{(b)}}$ & $\begin{array}{c}v_{\mathrm{LSR}}{ }^{(c)} \\
\left(\mathrm{km} \mathrm{s}^{-1}\right)\end{array}$ & $\begin{array}{c}\Delta v^{(d)} \\
\left(\mathrm{km} \mathrm{s}^{-1}\right)\end{array}$ & $\begin{array}{l}T_{A}^{*}(e) \\
(\mathrm{mK})\end{array}$ \\
\hline $\mathrm{CCO}$ & $1_{1}-0_{1}$ & $32623.449 \pm 0.007$ & $5.1 \pm 0.7$ & $5.57(05)$ & $1.09(13)$ & 4.5 \\
\hline $\mathrm{CCO}$ & $2{ }_{1}-1_{1}$ & $32738.613 \pm 0.005$ & $1.6 \pm 0.7$ & $6.33(18)$ & $1.46(34)$ & 1.0 \\
\hline $\mathrm{CCO}$ & $2_{3}-1_{2}$ & $45826.734 \pm 0.002$ & $8.1 \pm 0.9$ & $5.69(04)$ & $0.73(11)$ & 10.0 \\
\hline $\mathrm{CCO}$ & $2_{2}-1_{1}$ & $46182.187 \pm 0.002$ & $2.5 \pm 1.0$ & $5.73(17)$ & $0.89(31)$ & 2.7 \\
\hline $\mathrm{CCCO}$ & $4-3$ & $38486.891 \pm 0.001$ & $43.5 \pm 1.0$ & $5.74(01)$ & $0.63(07)$ & 64.5 \\
\hline $\mathrm{CCCO}$ & $5-4$ & $48108.474 \pm 0.001$ & $44.2 \pm 1.0$ & $5.75(01)$ & $0.63(14)$ & 66.4 \\
\hline HNCO & $2_{02}-1_{01} 1-1$ & $43962.007 \pm 0.030$ & $20.1 \pm 1.0$ & $5.76(01)$ & $0.62(02)$ & 35.1 \\
\hline HNCO & $2_{02}-1_{01} 1-2$ & $43962.641 \pm 0.006$ & & & & $\leq 2.7$ \\
\hline HNCO & $2_{02}-1_{01} 3-2$ & $43963.000 \pm 0.030$ & $178.8 \pm 1.0$ & $5.76(01)$ & $0.68(01)$ & 247.8 \\
\hline HNCO & $202-1_{01} 2-1$ & $43963.000 \pm 0.030$ & & & & \\
\hline HNCO & $2_{02}-1_{01} 1-0$ & $43963.626 \pm 0.030$ & $26.1 \pm 2.0$ & $6.35(02)$ & $0.60(04)$ & 41.2 \\
\hline HNCO & $2_{02}-1_{01} 2-2$ & $43963.626 \pm 0.030$ & $22.9 \pm 2.0$ & $5.66(03)$ & $0.64(05)$ & 33.6 \\
\hline HCNO & $2-1$ & $45876.069 \pm 0.002$ & $7.1 \pm 1.0$ & $5.79(08)$ & $0.98(16)$ & 6.9 \\
\hline $\mathrm{HOCN}$ & $2_{02}-1_{01}$ & $41950.836 \pm 0.001$ & $13.6 \pm 1.0$ & $5.55(02)$ & $0.82(03)$ & 15.6 \\
\hline $\mathrm{HCOOH}$ & $2{ }_{12}-1_{11}$ & $43303.705 \pm 0.001$ & $3.4 \pm 0.5$ & $6.10(09)$ & $0.61(10)$ & 5.2 \\
\hline $\mathrm{HCOOH}$ & $2_{02}-1_{01}$ & $44911.734 \pm 0.001$ & $6.7 \pm 0.5$ & $5.82(05)$ & $0.79(10)$ & 7.9 \\
\hline $\mathrm{HCOOH}$ & $2{ }_{11}-1_{10}$ & $46581.220 \pm 0.001$ & $2.1 \pm 0.5$ & $5.95(14)$ & $0.70(22)$ & 2.8 \\
\hline $\mathrm{HCCCHO}$ & $4_{14}-3_{13}$ & $36648.266 \pm 0.006$ & $7.4 \pm 0.5$ & $5.76(02)$ & $0.78(05)$ & 9.0 \\
\hline $\mathrm{HCCCHO}$ & $4_{04}-3_{03}$ & $37290.136 \pm 0.006$ & $21.0 \pm 0.5$ & $5.64(01)$ & $0.70(02)$ & 28.1 \\
\hline $\mathrm{HCCCHO}$ & $4_{13}-3_{12}$ & $37954.572 \pm 0.006$ & $10.4 \pm 0.5$ & $5.59(01)$ & $0.74(04)$ & 13.2 \\
\hline $\mathrm{HCCCHO}$ & $5{ }_{15}-4_{14}$ & $45807.708 \pm 0.007$ & $3.5 \pm 0.7$ & $5.73(05)$ & $0.46(10)$ & 7.3 \\
\hline $\mathrm{HCCCHO}$ & $5_{05}-4_{04}$ & $46602.868 \pm 0.007$ & $25.5 \pm 0.5$ & $5.64(01)$ & $0.65(02)$ & 3.6 \\
\hline $\mathrm{HCCCHO}$ & $5_{14}-4_{13}$ & $47440.427 \pm 0.007$ & $6.0 \pm 0.7$ & $5.61(04)$ & $0.55(09)$ & 10.3 \\
\hline $\mathrm{A}-\mathrm{CH}_{3} \mathrm{CHO}$ & $4_{04}-3_{13}$ & $32709.214 \pm 0.002$ & & & & $\leq 1.8$ \\
\hline $\mathrm{A}-\mathrm{CH}_{3} \mathrm{CHO}$ & $2_{12}-1_{11}$ & $37464.204 \pm 0.001$ & $12.1 \pm 1.0$ & $5.84(02)$ & $0.91(06)$ & 12.5 \\
\hline $\mathrm{A}-\mathrm{CH}_{3} \mathrm{CHO}$ & $2_{02}-1_{01}$ & $38512.079 \pm 0.001$ & $31.3 \pm 0.6$ & $5.85(01)$ & $0.82(01)$ & 35.7 \\
\hline $\mathrm{A}-\mathrm{CH}_{3} \mathrm{CHO}$ & $2{ }_{11}-1_{10}$ & $39594.289 \pm 0.001$ & $14.0 \pm 1.0$ & $5.83(02)$ & $0.79(05)$ & 16.6 \\
\hline $\mathrm{A}-\mathrm{CH}_{3} \mathrm{CHO}$ & $1_{10}-1_{01}$ & $47820.620 \pm 0.002$ & $4.3 \pm 0.6$ & $5.76(08)$ & $0.65(13)$ & 6.1 \\
\hline $\mathrm{A}-\mathrm{CH}_{3} \mathrm{CHO}$ & $22_{11}-2_{02}$ & $48902.831 \pm 0.002$ & $4.0 \pm 0.6$ & $5.76(07)$ & $0.66(13)$ & 5.6 \\
\hline $\mathrm{E}-\mathrm{CH}_{3} \mathrm{CHO}$ & $4_{+04}-3-13$ & $33236.468 \pm 0.002$ & & & & $\leq 2.0$ \\
\hline $\mathrm{E}-\mathrm{CH}_{3} \mathrm{CHO}$ & $2-12-1_{+10}$ & $35837.312 \pm 0.003$ & $1.3 \pm 0.6$ & $5.89(09)$ & $0.62(20)$ & 2.0 \\
\hline $\mathrm{E}-\mathrm{CH}_{3} \mathrm{CHO}$ & $2_{-12}-1_{-11}$ & $37686.932 \pm 0.002$ & $9.7 \pm 1.0$ & $5.88(02)$ & $0.75(05)$ & 12.1 \\
\hline $\mathrm{E}-\mathrm{CH}_{3} \mathrm{CHO}$ & $2+02-1+01$ & $38506.035 \pm 0.001$ & $33.7 \pm 1.0$ & $5.85(01)$ & $0.82(01)$ & 38.5 \\
\hline $\mathrm{E}-\mathrm{CH}_{3} \mathrm{CHO}$ & $2+11-1+10$ & $39362.537 \pm 0.002$ & $13.8 \pm 1.0$ & $5.82(02)$ & $0.84(04)$ & 15.4 \\
\hline $\mathrm{E}-\mathrm{CH}_{3} \mathrm{CHO}$ & $2+11-1-11$ & $41212.157 \pm 0.003$ & $2.5 \pm 0.8$ & $6.07(09)$ & $0.83(16)$ & 2.8 \\
\hline $\mathrm{E}-\mathrm{CH}_{3} \mathrm{CHO}$ & $1_{-11}-1_{+01}$ & $45897.347 \pm 0.003$ & & & & $\leq 3.0$ \\
\hline $\mathrm{E}-\mathrm{CH}_{3} \mathrm{CHO}$ & $1_{+10}-1_{+01}$ & $47746.968 \pm 0.002$ & $2.5 \pm 0.8$ & $6.17(22)$ & $0.82(23)$ & 2.8 \\
\hline $\mathrm{E}-\mathrm{CH}_{3} \mathrm{CHO}$ & $2+11-2+02$ & $48603.469 \pm 0.002$ & $6.8 \pm 1.0$ & $5.88(05)$ & $0.75(11)$ & 8.6 \\
\hline $\mathrm{o}-\mathrm{H}_{2} \mathrm{CCO}$ & $22_{12}-1_{11}$ & $40039.017 \pm 0.001$ & $57.8 \pm 0.7$ & $5.77(01)$ & $0.68(01)$ & 79.5 \\
\hline $\mathrm{o}-\mathrm{H}_{2} \mathrm{CCO}$ & $2{ }_{11}-1_{10}$ & $40793.842 \pm 0.001$ & $59.4 \pm 0.7$ & $5.79(01)$ & $0.68(01)$ & 81.9 \\
\hline $\mathrm{p}-\mathrm{H}_{2} \mathrm{CCO}$ & $2_{02}-1_{01}$ & $40417.950 \pm 0.001$ & $37.9 \pm 0.7$ & $5.78(01)$ & $0.64(02)$ & 55.9 \\
\hline o-c- $\mathrm{H}_{2} \mathrm{C}_{3} \mathrm{O}$ & $3_{13}-2_{12}$ & $39956.733 \pm 0.004$ & $14.9 \pm 0.8$ & $5.81(01)$ & $0.65(03)$ & 21.5 \\
\hline $\mathrm{o}-\mathrm{c}-\mathrm{H}_{2} \mathrm{C}_{3} \mathrm{O}$ & $3_{12}-2_{11}$ & $44587.397 \pm 0.004$ & $12.4 \pm 0.8$ & $5.82(01)$ & $0.51(03)$ & 22.8 \\
\hline p-c- $\mathrm{H}_{2} \mathrm{C}_{3} \mathrm{O}$ & $3_{03}-2_{02}$ & $42031.939 \pm 0.004$ & $6.4 \pm 0.8$ & $5.78(03)$ & $0.68(07)$ & 8.9 \\
\hline p-c- $\mathrm{H}_{2} \mathrm{C}_{3} \mathrm{O}$ & $3_{22}-2_{21}$ & $42316.187 \pm 0.003$ & $1.7 \pm 0.7$ & $5.78(02)$ & $0.27(10)$ & 6.0 \\
\hline p-c- $\mathrm{H}_{2} \mathrm{C}_{3} \mathrm{O}$ & $3_{21}-2_{20}$ & $42601.246 \pm 0.003$ & $2.4 \pm 0.7$ & $5.94(03)$ & $0.48(09)$ & 4.6 \\
\hline $\mathrm{HCCO}$ & $2,2.5-1,1.5 F=3-2$ & $43317.673 \pm 0.006$ & $4.9 \pm 0.8$ & $5.80(03)$ & $0.51(08)$ & 8.9 \\
\hline $\mathrm{HCCO}$ & $2,2.5-1,1.5 F=2-1$ & $43321.150 \pm 0.006$ & $3.8 \pm 0.8$ & $5.70(05)$ & $0.67(15)$ & 5.4 \\
\hline $\mathrm{HCCO}$ & $2,1.5-1,0.5 F=2-1$ & $43329.543 \pm 0.006$ & $3.8 \pm 0.8$ & $5.67(06)$ & $0.64(15)$ & 5.5 \\
\hline $\mathrm{HCCO}$ & $2,1.5-1,0.5 F=1-0$ & $43335.462 \pm 0.004$ & $4.2 \pm 0.8$ & $5.69(08)$ & $0.97(17)$ & 4.1 \\
\hline
\end{tabular}

Notes. ${ }^{(a)}$ Rest frequencies and uncertainties from MADEX (Cernicharo 2012). ${ }^{(b)}$ Integrated line intensity in mK kms ${ }^{-1}$. ${ }^{(c)}$ Local standard of rest velocity of the observed emission $\mathrm{kms}^{-1}$. ${ }^{(d)}$ Line width at half intensity derived by fitting a Gaussian line profile to the observed transitions (in $\left.\mathrm{kms}^{-1}\right) .{ }^{(e)}$ Upper limits to the antenna temperature correspond to $3 \sigma$ values. ${ }^{(f)}$ Average of two hyperfine components. 
Table A.2. continued.

\begin{tabular}{|c|c|c|c|c|c|c|}
\hline Molecule & Transition & $\begin{array}{l}v_{\text {rest }}(a) \\
(\mathrm{MHz})\end{array}$ & $\begin{array}{c}\left.\int_{(\mathrm{mK} \mathrm{km} \mathrm{s}} T_{A}^{*} \mathrm{~d} v^{(b)}\right) \\
\mathrm{km}^{-1}\end{array}$ & $\begin{array}{c}v_{\mathrm{LSR}}{ }^{(c)} \\
\left(\mathrm{km} \mathrm{s}^{-1}\right)\end{array}$ & $\begin{array}{c}\Delta v^{(d)} \\
\left(\mathrm{km} \mathrm{s}^{-1}\right)\end{array}$ & $\begin{array}{l}T_{A}^{*}(e) \\
(\mathrm{mK})\end{array}$ \\
\hline $\mathrm{HC}_{5} \mathrm{O}$ & $13112.5-12-111.513-12$ & $32267.964 \pm 0.002$ & $3.7 \pm 0.9$ & $5.52(06)$ & $0.63(09)$ & 5.6 \\
\hline $\mathrm{HC}_{5} \mathrm{O}$ & $13112.5-12-111.512-11$ & $32268.049 \pm 0.002$ & $4.8 \pm 1.0$ & $5.65(07)$ & $0.73(15)$ & 6.0 \\
\hline $\mathrm{HC}_{5} \mathrm{O}$ & $13-112.5-12111.513-12$ & $32271.760 \pm 0.002$ & $2.7 \pm 1.0$ & $5.59(08)$ & $0.62(14)$ & 3.9 \\
\hline $\mathrm{HC}_{5} \mathrm{O}$ & $13-1 \quad 12.5-12111.512-11$ & $32271.848 \pm 0.002$ & $4.3 \pm 1.0$ & $5.62(06)$ & $0.76(15)$ & 5.4 \\
\hline $\mathrm{HC}_{5} \mathrm{O}$ & $14-113.5-13112.514-13$ & $34849.461 \pm 0.002$ & $1.9 \pm 0.7$ & $5.58(02)$ & $0.33(16)$ & 5.0 \\
\hline $\mathrm{HC}_{5} \mathrm{O}$ & $14-1 \quad 13.5-13112.513-12$ & $34849.540 \pm 0.002$ & $4.5 \pm 1.0$ & $5.67(03)$ & $0.81(08)$ & 5.3 \\
\hline $\mathrm{HC}_{5} \mathrm{O}$ & $14113.5-13-112.514-13$ & $34853.387 \pm 0.002$ & $4.5 \pm 1.0$ & $5.69(17)$ & $0.74(14)$ & 5.7 \\
\hline $\mathrm{HC}_{5} \mathrm{O}$ & $14113.5-13-112.513-12$ & $34853.469 \pm 0.002$ & $3.1 \pm 0.9$ & $5.63(14)$ & $0.54(16)$ & 5.4 \\
\hline $\mathrm{HC}_{5} \mathrm{O}$ & $15114.5-14-113.515-14^{(f)}$ & $37430.982 \pm 0.003$ & $6.3 \pm 1.0$ & $5.79(03)$ & $0.93(05)$ & 6.4 \\
\hline $\mathrm{HC}_{5} \mathrm{O}$ & $15-114.5-14113.515-14^{(f)}$ & $37435.050 \pm 0.003$ & $6.2 \pm 1.0$ & $5.79(04)$ & $0.99(09)$ & 5.9 \\
\hline $\mathrm{HC}_{5} \mathrm{O}$ & $15-115.5-15114.516-15^{(f)}$ & $40012.451 \pm 0.004$ & $5.3 \pm 1.0$ & $5.80(06)$ & $1.00(12)$ & 4.9 \\
\hline $\mathrm{HC}_{5} \mathrm{O}$ & $15115.5-15-114.516-15^{(f)}$ & $40016.668 \pm 0.004$ & $7.1 \pm 1.0$ & $5.86(04)$ & $1.02(10)$ & 6.5 \\
\hline $\mathrm{HC}_{5} \mathrm{O}$ & $16116.5-15-115.517-16^{(f)}$ & $42593.906 \pm 0.004$ & $5.2 \pm 1.0$ & $5.70(05)$ & $0.77(09)$ & 6.3 \\
\hline $\mathrm{HC}_{5} \mathrm{O}$ & $16-116.5-15115.517-16^{(f)}$ & $42598.284 \pm 0.004$ & $5.4 \pm 1.0$ & $5.89(04)$ & $0.82(09)$ & 6.2 \\
\hline $\mathrm{HC}_{5} \mathrm{O}$ & $17-117.5-16116.518-17^{(f)}$ & $45175.346 \pm 0.005$ & $5.4 \pm 1.0$ & $5.75(11)$ & $1.05(19)$ & 4.8 \\
\hline $\mathrm{HC}_{5} \mathrm{O}$ & $17117.5-16-116.518-17^{(f)}$ & $45179.895 \pm 0.005$ & $6.3 \pm 1.0$ & $5.80(08)$ & $1.06(17)$ & 5.6 \\
\hline $\mathrm{HC}_{5} \mathrm{O}$ & $18118.5-17-117.519-18^{(f)}$ & $47756.772 \pm 0.007$ & & & & $\leq 5.1$ \\
\hline $\mathrm{HC}_{5} \mathrm{O}$ & $18-118.5-17117.519-18^{(f)}$ & $47761.501 \pm 0.007$ & & & & $\leq 5.1$ \\
\hline
\end{tabular}

Table A.3. Predicted frequencies of $\mathrm{HC}_{3} \mathrm{O}^{+}$.

\begin{tabular}{|c|c|c|c|c|c|}
\hline Transition & $\begin{array}{c}v \\
(\mathrm{MHz})\end{array}$ & $\begin{array}{l}\mathrm{E}_{u p} \\
(\mathrm{~K})\end{array}$ & $\begin{array}{c}\mathrm{A}_{i j} \\
\left(\mathrm{~s}^{-1}\right)\end{array}$ & $\mathrm{S}_{i j}$ & $\mathrm{~g}_{u}$ \\
\hline $1 \rightarrow 0$ & $8921.175 \pm 0.001$ & 0.4 & $2.92810^{-08}$ & 1 & 3 \\
\hline $2 \rightarrow 1$ & $17842.338 \pm 0.003$ & 1.3 & $2.81010^{-07}$ & 2 & 5 \\
\hline $3 \rightarrow 2$ & $26763.477 \pm 0.004$ & 2.6 & $1.01610^{-06}$ & 3 & 7 \\
\hline $4 \rightarrow 3$ & $35684.579 \pm 0.005$ & 4.3 & $2.49810^{-06}$ & 4 & 9 \\
\hline $5 \rightarrow 4$ & $44605.633 \pm 0.006$ & 6.4 & $4.99010^{-06}$ & 5 & 11 \\
\hline $6 \rightarrow 5$ & $53526.627 \pm 0.006$ & 9.0 & $8.75610^{-06}$ & 6 & 13 \\
\hline $7 \rightarrow 6$ & $62447.547 \pm 0.006$ & 12.0 & $1.40610^{-05}$ & 7 & 15 \\
\hline $8 \rightarrow 7$ & $71368.383 \pm 0.006$ & 15.4 & $2.11610^{-05}$ & 8 & 17 \\
\hline $9 \rightarrow 8$ & $80289.124 \pm 0.006$ & 19.3 & $3.03310^{-05}$ & 9 & 19 \\
\hline $10 \rightarrow 9$ & $89209.754 \pm 0.008$ & 23.5 & $4.18210^{-05}$ & 10 & 21 \\
\hline $11 \rightarrow 10$ & $98130.263 \pm 0.010$ & 28.3 & $5.59010^{-05}$ & 11 & 23 \\
\hline $12 \rightarrow 11$ & $107050.638 \pm 0.014$ & 33.4 & $7.28410^{-05}$ & 12 & 25 \\
\hline $13 \rightarrow 12$ & $115970.868 \pm 0.020$ & 39.0 & $9.29010^{-05}$ & 13 & 27 \\
\hline $14 \rightarrow 13$ & $124890.942 \pm 0.027$ & 45.0 & $1.16310^{-04}$ & 14 & 29 \\
\hline $15 \rightarrow 14$ & $133810.844 \pm 0.035$ & 51.4 & $1.43410^{-04}$ & 15 & 31 \\
\hline $16 \rightarrow 15$ & $142730.566 \pm 0.045$ & 58.2 & $1.74410^{-04}$ & 16 & 33 \\
\hline $17 \rightarrow 16$ & $151650.094 \pm 0.056$ & 65.5 & $2.09510^{-04}$ & 17 & 35 \\
\hline $18 \rightarrow 17$ & $160569.416 \pm 0.069$ & 73.2 & $2.49110^{-04}$ & 18 & 37 \\
\hline $19 \rightarrow 18$ & $169488.521 \pm 0.083$ & 81.3 & $2.93410^{-04}$ & 19 & 39 \\
\hline $20 \rightarrow 19$ & $178407.395 \pm 0.099$ & 89.9 & $3.42710^{-04}$ & 20 & 41 \\
\hline $21 \rightarrow 20$ & $187326.026 \pm 0.118$ & 98.9 & $3.97110^{-04}$ & 21 & 43 \\
\hline $22 \rightarrow 21$ & $196244.404 \pm 0.138$ & 108.3 & $4.57110^{-04}$ & 22 & 45 \\
\hline $23 \rightarrow 22$ & $205162.515 \pm 0.160$ & 118.2 & $5.22710^{-04}$ & 23 & 47 \\
\hline $24 \rightarrow 23$ & $214080.348 \pm 0.185$ & 128.4 & $5.94410^{-04}$ & 24 & 49 \\
\hline $25 \rightarrow 24$ & $222997.889 \pm 0.211$ & 139.1 & $6.72410^{-04}$ & 25 & 51 \\
\hline $26 \rightarrow 25$ & $231915.129 \pm 0.240$ & 150.3 & $7.56910^{-04}$ & 26 & 53 \\
\hline $27 \rightarrow 26$ & $240832.053 \pm 0.272$ & 161.8 & $8.48210^{-04}$ & 27 & 55 \\
\hline $28 \rightarrow 27$ & $249748.650 \pm 0.306$ & 173.8 & $9.46610^{-04}$ & 28 & 57 \\
\hline $29 \rightarrow 28$ & $258664.908 \pm 0.342$ & 186.2 & $1.05210^{-03}$ & 29 & 59 \\
\hline $30 \rightarrow 29$ & $267580.815 \pm 0.381$ & 199.1 & $1.16610^{-03}$ & 30 & 61 \\
\hline
\end{tabular}

